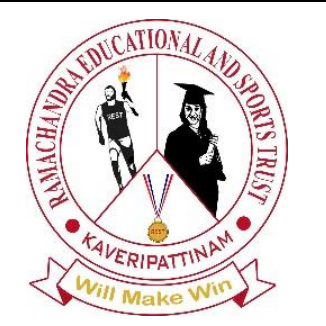

REST Journal on Emerging trends in Modelling and Manufacturing

Vol: 6(2), 2020

REST Publisher

ISSN: 2455-4537

Website: www.restpublisher.com/journals/jemm

\title{
Overview of different warehousing methodology for flexible manufacturing system ${ }^{1}$ Rohit Shelke, Pranav Parab, ${ }^{2}$ M. Ramachandran \\ ${ }^{1}$ MPSTME, SVKM'S NMIMS University, Shirpur, Dhule, Maharashtra, India \\ ${ }^{2}$ REST Labs, Kaveripattinam, Krishnagiri, Tamil nadu, India \\ sweetestchandran@gmail.com
}

\begin{abstract}
In today's progressive world of manufacturing system, warehousing is an important part of ours Supply chain. Warehouse can be represented as a building where we store our goods and warehousing as the processes or actions we do to improve the handling of material. In this paper we are going to discuss warehousing, Scheduling, warehouse management system, warehouse operations, travelling salesman problem and optimization. The brain of warehousing, warehouse management system plays a very significant role of controlling the operations and neatly optimizing the system. Main purpose of implementing all these systems is to save time, labour and space yet giving the good and satisfactory output to the customers. In workshop because of automation we have replaced the Machines with humans so for transporting of the job we use the line followed for some automated guided vehicles and arrange the machines in such a way that the production time should be less this problem comes with respect to delivery of the products or components from the warehouse. to encounter it manually we use the travelling salesman method so that it the transportation time should be reduced. a flexible manufacturing system opens the Gates to the new era of manufacturing systems. it is being a lot easier for us to control the structure and processing of a manufacturing system air production line. flexible management system is mainly used in almost every industry now because of its various advantages like Optimisation in work and increase in productivity. also FMS Technology or layout is also obtained by using the Optimisation techniques such as GA, SA.
\end{abstract}

Keywords: Warehouse management systems, Warehouse operations, Traveling salesman, flexible manufacturing system.

\section{Introduction}

\section{\&Warehousing}

In today's world of advanced manufacturing system chains Warehousing is the most important element. still This subject does not attract or gain attention from the students. But if you want to deliver customer its order on time we have to manage the inventory storage and warehousing efficiently because most of the processes air problems can be solved through these two. speaking of fish warehousing has not changed too much over the years but the techniques have been improved a lot. due to today's market which is mostly online the need of warehousing is more than the past few years .in other words we can say that we have the shortage of space for the warehouse so that we need more efficient and good warehousing system to deal with this whole problem.

\section{$*$ Scheduling}

Scheduling plays a very important role in warehousing IT controls all the actions and processes in a warehouse such as arranging of the good, controlling of the processes, and optimising the work on a production line. It is mainly used for planning the machinery resources, the human resources or any production processes or whether it is to be purchasing of new materials. it really works as an important tool in engineering. Without scheduling our whole system will be senseless it is the brain of the system which makes sure everything is according to our plan.

\section{\&Warehouse management systems}

Warehouse management system plays very significant role while managing the information of a warehouse. Whether it is about how much money, products, raw material we have and what is the location of it in the warehouse you can tell us all about it accurately without any mistake. because tracks product movements and its storage locations by all its activities from picking and investing. It integrates With our Freight Management System, sharing information such as customer details, consignments, addresses and freight charges.

\section{\&Warehouse operations}


The ultimate goal of these all operations is to improve the productivity of the warehouse i.e. making the small space more useful and Satisfying the customer needs efficiently with managing all the factors such as cost, the labour and making profit out of it. In other words, warehouses are the storage spaces where we put our all the material of products until we need them. it is the connecting Branch which connects the production department, the market, the customers and the suppliers.

\section{* Traveling salesman}

to provide these all products to the customers are the production systems we need to find the efficient way to reduce the travelling time. for that computation of time we have a brute force approach to find the shortest path for transportation. mainly it is recognised as the travelling salesman problem the nightmare of computational mathematicians. we have so many routs but we have to choose the shortest one for that the scientists or we can say the mathematicians have spent decades to solve this problem.

\section{* flexible manufacturing system}

To Bond these all operations, we have manufacturing system, Flexible management system as the name suggests it is a manufacturing system having flexibility which allows the system to react whenever there is a slightest change. in other words, it has the flexibility or ability to change the order of operations executed on a product Unlike other systems which are only made for only one product or the same production We can make Eke a wide variety of products within the single system by arranging the Machines according to our flexible manufacturing system layout. the layout depends on our purpose we can make it on a paper according to the processes that are going to be done on the product so the time is reduced and flexibility is increased in a production system.

\section{\&Optimization}

To make the improvements in a flexible manufacturing system we have to optimise the processes and upgrade it day by day with new technologies such as algorithm, automation systems air new advanced machineries. the most popular algorithms are GA, SA and particle Swarm Optimisation. In some warehouses we use automated guided vehicles also so that the human labour should be at a very low scale and the productivity will be increased.

\section{Inside Information}

\section{\&Warehousing}

Now in the today's world of automation warehousing has been the most important factor of the manufacturing industry because of which the less space is utilised more efficiently and planning of the storing to the delivery of the product is has been easy for the industries. reduces that Lead time of the product development and supply chain processes. The researches have decoded all the processes which are done in in warehousing first one is receiving of the product, then transferring of the product, then comes handling, storage the packing of product and the expediting process. the warehousing issues are main focus today because of its increasing value and role in in the supply chain. Before all this Industries needed very large space and more facilities TO Store the items in racks and the loading, unloading and moving of the products from it was very hectic but now it's a lot easier for us to manage all these things by the help of automation.

\section{\& Scheduling}

Flexible Manufacturing system is all good in terms of its advantages but it is a very complicated, large scale system made with the combination of hardware and software's. All the problems or difficulties comes in this system needs an expert for handling it. Every section / department plays an important role in the warehouse. From importing of the new components to storing them till dispatching and transporting it to the customer we have all the systems automated and each system has its own unique algorithms to work efficiently with minimum time and labour. Nowadays mostly in every big warehouse the dispatching algorithm is used at very basic level the highest application depends on the requirement of the company and the latest technology they have. Now days some companies are using machine learning for learning through the mistakes to make it possible to automate the whole workstation and also working on how to troubleshoot the problems on its own.

\section{\&Warehouse management systems}

Obviously the automated warehouse has become the need of the modern logistic system. Because why not? It has got all the advantages that an industry need:

1. It saves land

2. Reduces the labour intensity

3. $\quad$ Reduces the close gaps

4. The management quality is increased

5. $\quad$ Outages are reduced

6. Increased efficiency of logistics

And if all these things come altogether the money is literally saved and company gains more profit and due to the good service to the customer company grows rapidly. Warehouse management system works not for only on sector of the industry it has all the information about inventory, storage, its location the available and dispatch stock of it. And accountability 
matters the most for a great business not the production, not quantity these all things are supportive but for taking company to touch the skies we need to do proper management. Some companies have introduced the so called 'Artificial intelligence' systems so that they can track the record and predict / decide what actions should be taken in the workplace. To make this happen we use different kind of sensors and controllers. These all upgradations are always necessary for a system so that its efficiency and productivity increases.

\section{*Warehouse operations}

The main purpose today is enhancing the warehouse operations as much as possible. For that the industries have Radio frequency based technologies as well as mobile technology which uses a customized case-based retrieval engine to precisely track, locate and manage the resources in the warehouse environment. The system design and structure is combined with 2 elements the hardware and the software part. There is no doubt that the warehouse operations are affected by that. Every single factor in a warehouse is depended on each other. All the factors like the moving to input to the warehouse to the dispatching for the customer all the processes are affected. As a product is moved from its stored position the system calculates all the possibilities that can be done so that the space can be used effectively according to the dimensions of other products. Also changes in demand of the customer changes the whole planning of operations. All the inventory, import of material everything is changed accordingly. Now here comes the problem that we have less time and more work to do.

\section{*Traveling salesman}

For that problem we have the technique to manage the time of doing work in less time, the travelling salesman theory. Generally, it is always introduced as a problem but it is the most preferred and useful solution for the time management. The mathematicians have given decades to solve this problem. Mainly it is used for calculation of the shortest possible route for the transportation of the goods to the customer. A Lot of factors are involved in it such that the weight of the consignment, its material, size, from what territory it will be easy and safe to travel. The short route doesn't always mean that the time required is less, it differs by the product only. For example, there are two companies A \& B. Both are located at GOA.Company A provides some raw material and B provides some fragile material made sculptures and both have to delivery at Srinagar which one delivers the orders first? Now in this a normal person can say the fragile one as it can be delivered by aeroplanes and raw material by road in trucks. Now, here comes the tricky part not always things work like this the transportation of components is based on their weight, its casualties, its travelling path, there is a special team of people who lead the transportation process.

\section{* flexible manufacturing system (FMS)}

Mainly the flexible manufacturing system is advancing by day by day. Industries are making it automated by implementing the more and more advanced technologies. From loading of the material on the machine to picking up the manufactured product and taking the manufactured product to the warehouse storage spaces and keeping the track of every single thing that is happening in the workplace truly Flexible manufacturing system is a superpower of the world of manufacturing. The stations ae mainly designed and programmed as per our requirements so that the work processes are enhanced and time is saved. Nowadays the warehouse can be handled by few persons only. The advanced controllers like PLC, Automated guided vehicles, SCADA systems the transportation of the products, maintaining the storage and logistics is a lot easier. The lead time of the machineries and many other processes is reduced. Because that's what Flexible manufacturing systems are for they mild according to our purposes. Now as per the future aspect industries are working on the lights out manufacturing in which there will be no interface of human at all it will the one best thing for the industries but for the labours it is like a nightmare. For some extent this is a myth because if the new systems arrive in market there will be need of the new technical engineers which can resolve the issues of that new technologies.

\section{*Optimization}

Along with all these technologies we use the real time optimizers which are the only things that optimize the operations in little spans. This happens in short processes like improving in the material handling system, improvement in storage system, improvement in the transportation system. Because even the small change makes the big difference. Optimization has a lot of bright sides that makes it most important factor of manufacturing system, such as better performance of the work stations, simplification in design implementation and testing of the handling sequences.

\section{Conclusion}

Warehousing is very important at all the work places, which reduces the time and required expenses. It also protects the goods and services by wastage, damage, etc. warehousing results in the low risks and the low accidents. scheduling is must in a warehouse for arranging, controlling and Optimising the work processes in the production system because of scheduling it is a lot easier to manage the warehouse operations. The scheduling algorithms are the soul of the whole system without it, it is just a manual system. The algorithms make it the optimization part more successful and make the workplace work as per the schedule. warehouse management system work like a brain for the production system which controls and manages all the actions in a warehouse properly and systematically so that the productivity, visibility of the work and efficiency is increased. 
This warehouse management system also varies from simple to complex form according to the warehouse applications and processes included in it. Use of effective inventory management practices and real time information visibility can help to provide numerous benefits for your business including:

- Reduction in out-of-stock instances and manufacturing component shortages

- Improvement in the quality of decision-making for your business

- Enhanced communication effectiveness across your business and supply chain

- Reduction in inventory carrying costs

- Greater responsiveness and accuracy when dealing with product recalls

- Reduction in inventory theft

- Enhanced customer satisfaction rates.

Truly we can say flexible manufacturing system in is the only thing which is leading us to the future of manufacturing technology. As we know FMS is not a fixed technology or something the flexible it is in its name so it can be designed for flexibility according to the company's needs and the structure or the purpose of the products they are making. With all the qualities flexible manufacturing system has become the basic need of every industry to be implemented And of course the reason is its good quality of products and new technologies that are hand included day-by-day to reduce the human labour and increase the productivity of this workstation. this is not the opinion of only one person not to our company it is been observed from the server that takes your manager system as shown very good and unbelievable results in larger number of manufacturing industries like Amazon, Flipkart, ABB and many more automated industries. Also GA gives best solutions i.e. minimum waiting times of batch and machines respectively for all the cases rather than few exceptional cases where PSO and SA performs in a better way.

\section{References}

[1].Mishra, Nishikant, Vikas Kumar, Niraj Kumar, Maneesh Kumar, and Manoj Kumar Tiwari. "Addressing lot sizing and warehousing scheduling problem in manufacturing environment." Expert Systems with Applications 38, no. 9 (2011): 1175111762.

[2].Zhou, Chuanhong, and Qi Fei. "Warehouse management system development base on open source web framework." In 2016 International Conference on Industrial Informatics-Computing Technology, Intelligent Technology, Industrial Information Integration (ICIICII), pp. 65-68. IEEE, 2016.

[3].Daniels, Richard L., Jeffrey L. Rummel, and Robert Schantz. "A model for warehouse order picking." European Journal of Operational Research 105, no. 1 (1998): 1-17.

[4].Manzini, Riccardo, Alessandro Persona, and Alberto Regattieri. "Framework for designing and controlling a multicellular flexible manufacturing system." International Journal of Services and Operations Management 2, no. 1 (2006): 1-21.

[5].Amato, Francesco, Francesco Basile, Ciro Carbone, and Pasquale Chiacchio. "An approach to control automated warehouse systems." Control Engineering Practice 13, no. 10 (2005): 1223-1241.

[6].Chen, Kai-Ying, and Chun-Jay Chen. "Applying multi-agent technique in multi-section flexible manufacturing system." Expert Systems with Applications 37, no. 11 (2010): 7310-7318.

[7].Rizzi, Antonio, and Roberto Zamboni. "Efficiency improvement in manual warehouses through ERP systems implementation and redesign of the logistics processes." Logistics Information Management (1999).

[8].Gunasekaran, A., H. B. Marri, and F. Menci. "Improving the effectiveness of warehousing operations: a case study." Industrial Management \& Data Systems (1999).

[9].Mayank Jain, M. Ramachandran, Buy/Make decision making framework for pump product development with multi criteria decision making, International Journal of Applied Engineering Research. ISSN 0973-4562 Volume 10, Number 11 (2015) pp. 10486-10489.

[10].Altarazi, Safwan A., and Maysa M. Ammouri. "Concurrent manual-order-picking warehouse design: a simulation-based design of experiments approach." International Journal of Production Research 56, no. 23 (2018): 7103-7121.

[11].Cheng, Luo, Xu Didi, Lai Mingyong, and Wang Yan. "Design and implement of warehouse management system based on AOP." In 2006 IEEE International Engineering Management Conference, pp. 243-246. IEEE, 2006.

[12].Ascheuer, Norbert, Martin Grötschel, and Atef Abdel-Aziz Abdel-Hamid. "Order picking in an automatic warehouse: Solving online asymmetric TSPs." Mathematical Methods of Operations Research 49, no. 3 (1999): 501-515.

[13].Chan, F. T. S., and H. K. Chan. "Dynamic scheduling for a flexible manufacturing system-the pre-emptive approach." The International Journal of Advanced Manufacturing Technology 17, no. 10 (2001): 760-768.

[14].Kumar, V., Nishikant Mishra, Felix TS Chan, and A. Verma. "Managing warehousing in an agile supply chain environment: An F-AIS algorithm-based approach." International Journal of Production Research 49, no. 21 (2011): 64076426.

[15].Lu, Wenrong, Vaggelis Giannikas, Duncan McFarlane, and James Hyde. "The role of distributed intelligence in warehouse management systems." In Service orientation in holonic and multi-agent manufacturing and robotics, pp. 63-77. Springer, Cham, 2014.

[16].Simran Agarwal, M. Ramachandran, Optimization of Biomedical Waste Disposal Strategy by Fussy Topsis Method, International Journal of Research in Ayurveda and Pharmacy, 7(2):67-70 - April 2016. 
[17].Chow, Harry KH, King Lun Choy, Wing Bun Lee, and K. C. Lau. "Design of a RFID case-based resource management system for warehouse operations." Expert systems with applications 30, no. 4 (2006): 561-576.

[18].Önüt, Semih, Umut R. Tuzkaya, and Bilgehan Doğaç. "A particle swarm optimization algorithm for the multiple-level warehouse layout design problem." Computers \& Industrial Engineering 54, no. 4 (2008): 783-799.

[19].Baker, Peter, and Zaheed Halim. "An exploration of warehouse automation implementations: cost, service and flexibility issues." Supply Chain Management: An International Journal (2007).

[20].Lee, C. K. M., Yaqiong Lv, K. K. H. Ng, William Ho, and K. L. Choy. "Design and application of Internet of thingsbased warehouse management system for smart logistics." International Journal of Production Research 56, no. 8 (2018): 2753-2768.

[21].Draganjac, Ivica, Damjan Miklić, Zdenko Kovačić, Goran Vasiljević, and Stjepan Bogdan. "Decentralized control of multi-AGV systems in autonomous warehousing applications." IEEE Transactions on Automation Science and Engineering 13, no. 4 (2016): 1433-1447.

[22].de Koster, MBM de, and P. M. J. Warffemius. "American, Asian and third-party international warehouse operations in Europe." International Journal of Operations \& Production Management (2005).

[23].Rizzi, Antonio, and Roberto Zamboni. "Efficiency improvement in manual warehouses through ERP systems implementation and redesign of the logistics processes." Logistics Information Management (1999).

[24].Azadeh, Kaveh, René De Koster, and Debjit Roy. "Robotized and automated warehouse systems: Review and recent developments." Transportation Science 53, no. 4 (2019): 917-945.

[25].M. Ramachandran, V.Aji, A review on Development of a Three Axis Modern pneumatic Trailer applicable to shipping industry, International Journal of Applied Engineering Research. ISSN 0973-4562 Volume 10, Number 11 (2015) pp. 1057510579. 